\title{
ANALYTICAL AND EXPERIMENTAL INVESTIGATION ON SISAL FIBERS REINFORCED POLYMER COMPOSITES IN AVIATION
}

\author{
Sridhar K \\ Department of Aeronauical Engineering \\ Nitte Meenakshi Institute of Technology, Bangalore
}

\author{
Suresh P \\ Department of Aeronauical Engineering \\ Dayananda Sagar College of Engineering, Bangalore.
}

\begin{abstract}
The present work aims to analyze the mechanical characteristics of sisal fiber over other natural fibers and non-natural fibers. Over the past decades, natural fibers are established as promising raw material for development of major components in the field of automobile and aviation industry. Sisal fibers are extracted from Agave sisal Ana plant and fibers sheets have been prepared in bidirectional method and reinforced with epoxy, followed up angle ply laminate using hand layup technique. After curing, laminate was cut by CNC machine as per ASTM standards. The mechanical properties were determined and observed that the strength properties were found lower than the glass fiber reinforced composites. However these natural fiber composites have enough strength and stiffness and could be used in various non- structural critical components in aviation and automobile industries for the problem of weight penalty.
\end{abstract}

Index Terms: Composite materials, Epoxy, Hand layup, Natural fibers, Sisal fiber

\section{INTRODUCTION}

Composite materials, ceramics and plastics have been widespread prominent materials over last three decades. Because of these good mechanical properties, recyclability eco friendly- sustainable production and its wide range of application, so that natural-based reinforced composites are leading a major role within the structural community. The sisal fiber to enact as an excellent reinforcement materials and high machinability leads low cost for extraction from plants [12]. Amongst different natural fibers, the sisal fibers have excellent impact strength, good tensile and flexural strength

\author{
Suthan R \\ Department of Aeronauical Engineering \\ Nitte Meenakshi Institute of Technology, Bangalore \\ Sivakumar P \\ Department of Aeronauical Engineering \\ Sri Ramakrishna Engineering College,Coimbatore
}

compared to other lignocelluloses fibers [8]. These materials have very less density, enough specific properties, and biodegradable and non abrasive; due to this uniqueness of these materials it has a great connotation in the automobile and transportation industry. When compared to conventional fiber composites these natural fiber composites producing equal amount of properties [3]. Natural polymer fibers has a considerable demerits such as liquid absorption, less resistance to the fire and due its lesser amount of mechanical properties, it has a limited application. [9].Some following factors such as chemical treatment, load on the fibers, hybridization, dimension and size of fibers are affecting the mechanical properties of its polymer composites. By adding different fibers and fillers, the specific properties would be elevated according to purpose and requirement of strength [10]. These properties of the natural fibers inspired to explore the possible use of natural fibers as a substitute for synthetic fibers. This work intention is to meet the required mechanical properties of composite material by using natural fibers which is impregnated with suitable polymer.

\section{METHODOLOGY AND MATERIALS USED}

\subsection{Fabrication of composite}

In fabrication process the conventional hand layup has been adopted. The Harder HY917 and epoxy were mixed in the ratio of 1:10 and sisal fibers were applied as reinforcement. Sisal fiber properties are shown in below Table 1. After reinforcement of the fiber then it will be rolled by using roller to remove the air inside to avoid the voids. Then it is kept in mould for one day under the load of 5000 grams to make the laminate. 
TABLE 1. Sisal Fibers Properties

\begin{tabular}{lc}
\hline Property & sisal fiber \\
& \\
\hline Diameter $(\mu \mathrm{m})$ & $100-300$ \\
Density $(\mathrm{g} / \mathrm{cm} 3)$ & 1.45 \\
Cellulose & $65-78$ \\
Hemicelluloses $(\%)$ & $10-14$ \\
Pectin $(\%)$ & 10 \\
Lignin $(\%)$ & 9.9 \\
Wax $(\%)$ & 2.0 \\
Elongation at break $(\%)$ & $4-9$ \\
\hline
\end{tabular}

\subsection{Specimen testing}

\section{Tensile test}

To find the load required to break a natural fiber polymer composites specimen, ASTM D638 tensile testing has been used and it ill elongated to its breaking point. The figure shows the test specimen with standard size for testing.

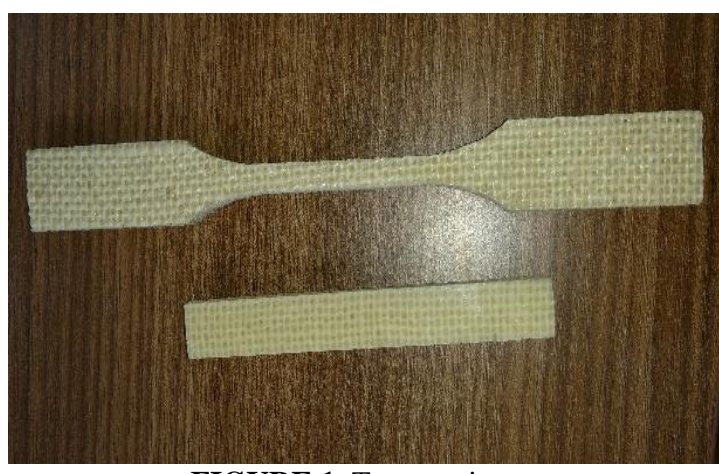

FIGURE 1. Test specimen.

Test specimen prepared as per ASTM 638 - I \& II standard size and dimensions are shown below.

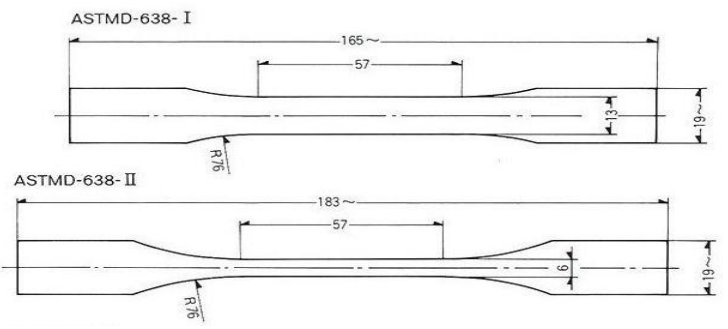

FIGURE 2. ASTM 638 - I \& II standard size.

Compression testing and three points bend test

ASTM D790 standard size has been considered for preparing test specimen.

TABLE 2. ASTM D790 standard size

\begin{tabular}{|c|c|}
\hline $\begin{array}{c}\text { Compression test }- \text { specimen } \\
\text { size }\end{array}$ & $\begin{array}{c}\text { Three point bend test - } \\
\text { specimen size }\end{array}$ \\
\hline Width- $25 \mathrm{~mm}$ & Width $-12.5 \mathrm{~mm}$ \\
\hline Length- $100 \mathrm{~mm}$ & Length $-100 \mathrm{~mm}$ \\
\hline
\end{tabular}

The specimen is subjected to compressive load to the unsupported center 12 to $25 \mathrm{~mm}$ gauge length of specimen in compression test. The wedges are inserted into the compression fixture, and extensometer is used to find the stain on specimen. He test results were affected based on specimen preparation, environmental conditions and method of conduction of test. The specimen is kept on the two supports and load has been applied at the third point (at center) in constant rate until specimen fails.

The above mentioned tests were conducted at the ADVANCED METALLURGICAL LABORATORYBANGALORE based on the ASTM standards.

\section{Laminate stiffness analysis}

To obtain the required stiffeners and strength in the required directions, the plies and bonded and stacked one over the other to act as single laminate and by changing the orientation of the fibers in each ply relative to common laminate reference axes.

TABLE 3. Sisal- epoxy - Material properties

\begin{tabular}{|c|c|c|c|c|}
\hline \multicolumn{5}{|c|}{ Sisal-epoxy - material properties } \\
\hline $\mathrm{E}_{1}\left(\mathrm{kN} / \mathrm{mm}^{2}\right)$ & $\mathrm{E}_{2}\left(\mathrm{kN} / \mathrm{mm}^{2}\right)$ & $\mathrm{G}_{12}\left(\mathrm{kN} / \mathrm{mm}^{2}\right)$ & $v_{12}$ & $v_{21}$ \\
\hline 45.9 & 45.9 & 17.65385 & 0.3 & 0.3 \\
\hline
\end{tabular}

\section{Laminate equivalent constant}

To determine the elastic constants in the membrane and bending mode by considering $7.2 \mathrm{~mm}$ thickness of laminate having membrane and bending compliance and shown below.

TABLE 4. Material property

\begin{tabular}{|c|c|c|}
\hline Material property & Membrane mode & Bending mode \\
\hline $\mathrm{E}_{1}\left(\mathrm{kN} / \mathrm{mm}^{2}\right)$ & 45.9 & 45.9 \\
\hline $\mathrm{E}_{2}\left(\mathrm{kN} / \mathrm{mm}^{2}\right)$ & 45.9 & 45.89999 \\
\hline $\mathrm{G}_{12}\left(\mathrm{kN} / \mathrm{mm}^{2}\right)$ & 17.65385 & 17.65384 \\
\hline$v_{\mathrm{xy}}$ & 0.3 & 0.3 \\
\hline$v_{\mathrm{yx}}$ & 0.3 & 0.3 \\
\hline $\mathrm{M}_{\mathrm{x}}$ & -0.00029 & 0.000169 \\
\hline $\mathrm{M}_{\mathrm{y}}$ & -0.00029 & -0.00056 \\
\hline
\end{tabular}

III. RESULT AND DISCUSSION

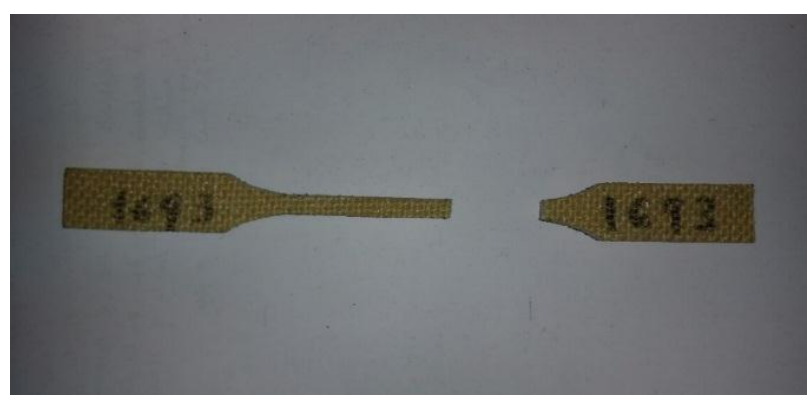




\section{International Journal of Engineering Applied Sciences and Technology, 2019 \\ Vol. 4, Issue 1, ISSN No. 2455-2143, Pages 94-97 \\ Published Online May 2019 in IJEAST (http://www.ijeast.com)}

FIGURE 3a. Tested specimen in tension test

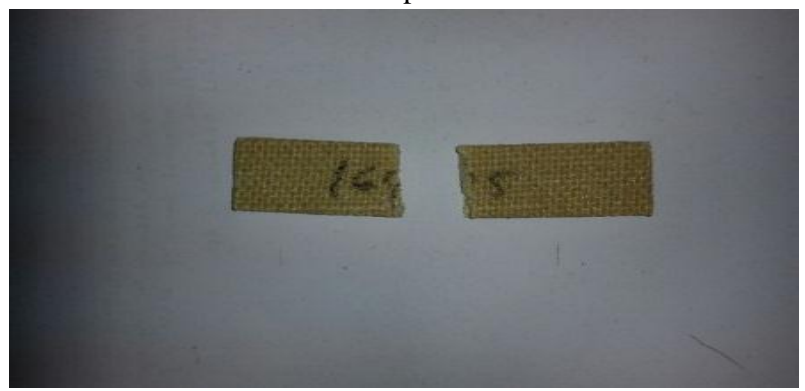

FIGURE 3b Tested specimen in compression test

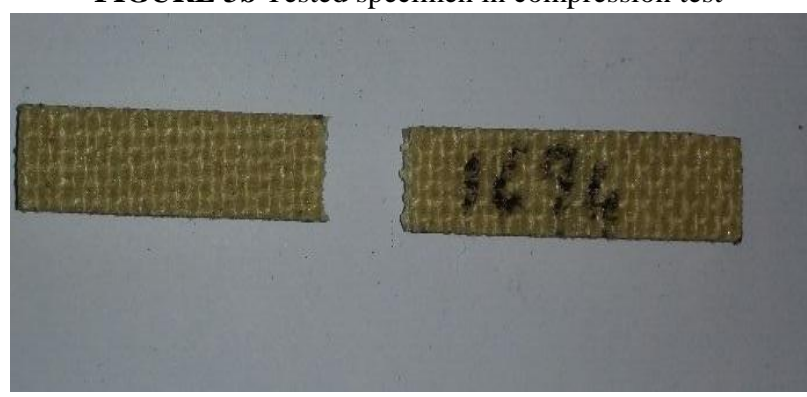

FIGURE 3c Tested specimen in bending test

\section{Results of tension test}

The maximum peak load absorbed was about $1600 \mathrm{~N}$ and corresponding tensile strength was found to be $37.08 \mathrm{GPa}$. The yield strength of the composite was found to be $30.57 \mathrm{GPa}$ and the total percentage elongation was $0.08 \%$.

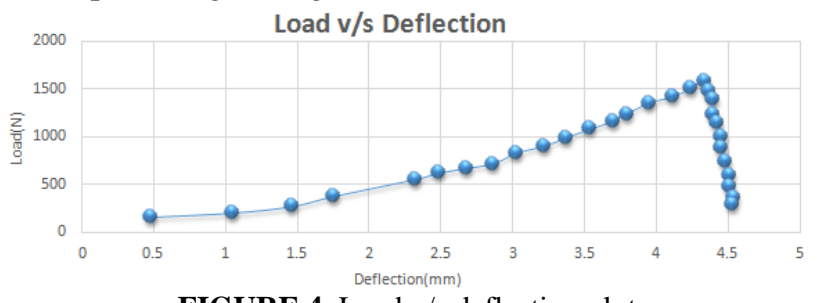

FIGURE 4. Load v/s deflection plot

A plot of load versus corresponding deflection for the tension test is given above this clearly indicates that the maximum load that the natural composite could withstand is about 1591 $\mathrm{N}(163.15 \mathrm{Kg})$. The plot has a steep slope indicating that the rate of deformation is low, indicating the sample holds it dimensions at the peak load condition.

\section{Results of compression test}

Similarly the compression test was performed on the specimen using UTM as per ASTM standards.

The peak load was absorbed was about $8400 \mathrm{~N}$ with the corresponding compression strength of $46 \mathrm{GPa}$.

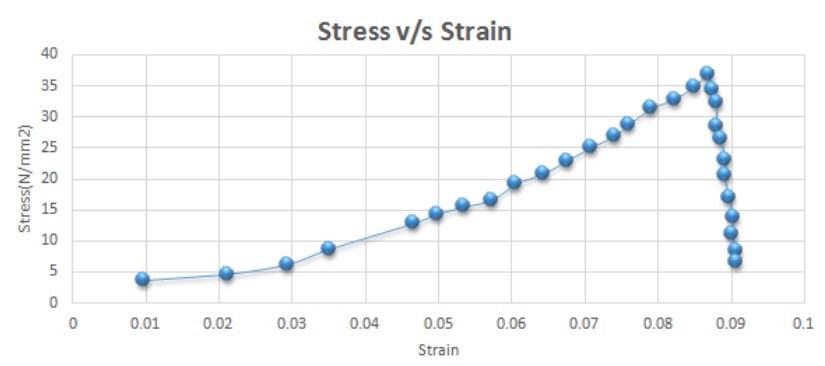

FIGURE 4. stress v/s strain plot

plot represents the stress versus strain plot for the tension test, the stress strain curve is one of the major parameter to access the mechanical properties of a materials also the slope of the curve gives the axial young's modulus of the natural composite. Plot 6.2 represents a typical behavior of a composite material, and the steep curve indicates a higher stiffness value. A best fit curve slope is plotted and the value of the young's modules is found to be E1=46.31 GPa which is in accordance with the predicted value of $45.9 \mathrm{GPa}$ using analytical calculations.

\section{Results of bending test}

Similar to the above test the three point bending test was carried out on the bending test machine as per ASTM standards. The maximum bending deflection absorbed was $3.62 \mathrm{~mm}$. The obtained are convincing, modulus of elasticity of the material is determined by finding the slope of stress vs strain plot. The load vs deflection plot for the tension test shown in the following results is digitalized and stress vs strain graph was developed. The slope of this plot gives young's modulus in primary direction.

\section{CONCLUSION}

From the experimental and analytical assessment the following conclusion has been made for sisal fibers reinforced polymer composites.

- A multi layered composite by reinforcing with eco friendly, light weight and low cost natural sisal fibers using an epoxy resin matrix.

- The maximum of tensile strength and flexural load $37.08 \mathrm{MPa}$ and $260 \mathrm{MPa}$ respectively was noticed by the composite.

- The maximum stresses $30.6 \mathrm{~N} / \mathrm{mm}^{2}, 46 \mathrm{~N} / \mathrm{mm}^{2}$, $2.776 \mathrm{~N} / \mathrm{mm}^{2}$, has been absorbed by the composite during tensile testing, compressive loading and flexural loading respectively.

- The strength properties has been found not good as those of the glass fiber reinforced composites. However these natural sisal fiber composite have enough strength and stiffness to be used in various non structurally critical components. 


\section{International Journal of Engineering Applied Sciences and Technology, 2019 \\ Vol. 4, Issue 1, ISSN No. 2455-2143, Pages 94-97 \\ Published Online May 2019 in IJEAST (http://www.ijeast.com)}

\section{REFERENCES}

[1]. Maria MRAZOVA. (2013). Advanced composite materials of the future in aerospace industry, INCAS BULLETIN, Volume 5, Issue 3, pp. 139 - 150.

[2]. Giuseppe Cristaldi, Alberta Latteri, Giuseppe Recca and Gianluca Cicala, Composites Based on Natural Fiber Fabrics.

[3]. D. NABI SAHEB and J. P. JOG, Natural Fiber Polymer Composites: A Review, Advances in Polymer Technology, Vol. 18, No. 4, 351-363.

[4]. Begum K. and Islam M.A. Natural Fiber as a substitute to Synthetic Fiber in Polymer Composites: A Review, Research Journal of Engineering Sciences, Vol. 2(3), 4653.

[5]. Kuruvilla Joseph1, Romildo Dias Tolêdo Filho2, Beena James3, Sabu Thomas4 \& Laura Hecker de Carvalho5, A REVIEW ON SISAL FIBER REINFORCED POLYMER COMPOSITES, Revista Brasileira de Engenharia Agrícola e Ambiental, v.3, n.3, p.367-379.

[6]. D. Chandramohan \& K. Marimuthu. (2011) A REVIEW ON NATURAL FIBERS, IJRRAS 8 (2), www.arpapress.com/Volumes/Vol8Issue2/IJRRAS_8_2_ 09.pdf 194.

[7]. Dr P V Senthiil, Aakash Sirsshti, Studies on Material and Mechanical Properties of Natural Fiber Reinforced Composites. The International Journal of Engineering And Science (IJES), Volume 3, Issue 11, Pages 18-27.

[8]. LaythMohammed, M. N. M. Ansari, Grace Pua, Mohammad Jawaid, and M. Saiful Islam. (2015). A Review on Natural Fiber Reinforced Polymer Composite and Its Applications, Hindawi Publishing Corporation, International Journal of Polymer Science, Volume 2015, Article ID 243947, 15 pages.

[9]. K. Senthilkumar, N. Saba, N. Rajini, M. Chandrasekar, M. Jawaid, Suchart Siengchin, Othman Y. Alotman, Mechanical properties evaluation of sisal fiber reinforced polymer composites: A review.

[10]. Mohit Sood ,Dharmpal Deepak,V.K. Gupta. (2018), Tensile properties of sisal fiber / recycled polyethylene (high density) composite: Effect of fiber chemical treatment, ICMPC 2017, Materials Today: Proceedings 5 $5673-5678$.

[11]. Ahmed Belaadi, Abderrezak Bezazi, Mostefa Bourchak, Fabrizio Scarpa, Tensile static and fatigue behaviour of sisal fibers, Materials and Design 46 (2013) 76-83.

[12]. R. S. Rana, Ashish kumre, Saraswati Rana and Rajesh Purohit, (2017), Characterization of Properties of epoxy sisal / Glass Fiber Reinforced hybrid composite, (ICMPC 2016), Materials Today: Proceedings 4, 54455451.

[13]. Hari Om Maurya, M.K. Gupta, R.K. Srivastava, H. Singh,( 2015 , Study on the mechanical properties of epoxy composite using short sisal fiber, 4th International
Conference on Materials Processing and Characterization, Materials Today: Proceedings 2, 1347 - 1355.

[14]. Adriana R. Martin, Maria Alice Martins, Odilon R.R.F. da Silva , Luiz H.C. Mattoso, (2010) , Studies on the thermal properties of sisal fiber and its constituents, Thermochimica Acta 506 14-19. 